\title{
Geographical chemical variability and processing oxidation of volatile compounds of Casearia sylvestris leaves
}

Flavio Alexandre Carvalho ${ }^{1} \oplus$, Fernando Bombarda Oda ${ }^{1} \oplus$, Antônio Eduardo Miller Crotti ${ }^{2}$, Eduardo José Crevelin ${ }^{2}{ }^{\oplus}$, André Gonzaga dos Santos ${ }^{1+}$ (6)

1. São Paulo State University, School of Pharmaceutical Sciences, Araraquara, Brazil.

2. University of São Paulo, Faculty of Philosophy, Sciences and Letters, Ribeirão Preto, Brazil.

+Corresponding author: André Gonzaga dos Santos, Phone: +55 (16) 33016994, Email address: andre.gonzaga@unesp.br

\section{ARTICLE INFO}

Article history:

Received: February 09, 2021

Accepted: April 20, 2021

Published: July 01, 2021

Section Editor: Assis Vicente Benedetti

\section{Keywords}

1. Essential oil

2. artifacts

3. sesquiterpenes

4. hydrodistillation

5. thermal desorption

ABSTRACT: The Casearia sylvestris Sw. dried leaf essential oil (EO) contains sesquiterpenes as the main components. However, the volatile components in the in natura leaves remain unknown. This study compares the volatile chemicals in the in natura leaves and dried leaf EO of two $C$. sylvestris populations from Atlantic Forest and Cerrado. The volatile compounds were directly analysed by thermal desorption (TD) coupled to gas chromatography mass spectrometry (GCMS); the dried leaf EO composition was determined by GC-MS. All the identified compounds were sesquiterpenes, and the major components were $(E)$-caryophyllene, bicyclogermacrene, $\beta$-elemene, spathulenol, and caryophyllene oxide. In both populations, the sesquiterpene hydrocarbon content and the oxygenated sesquiterpene content respectively decreased and increased on going from the in natura leaves to the dried leaf essential oil, indicating that drying and/or hydrodistillation modified the volatile chemical composition by generating oxidation artifacts. Results suggested that $(E)$-caryophyllene and bicyclogermacrene may be oxidized during the process to yield caryophyllene oxide and spathulenol, respectively. The two $C$. sylvestris populations also differed in terms of volatile chemical composition.

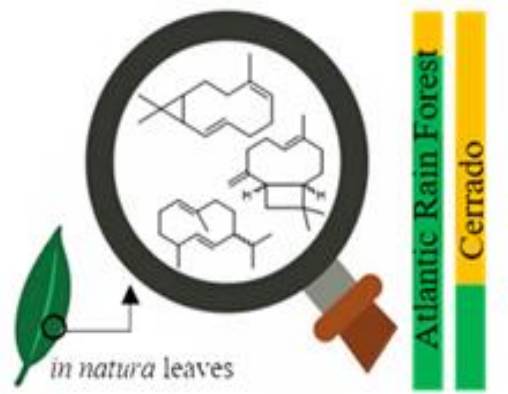

Sesquiterpene hydrocarbons

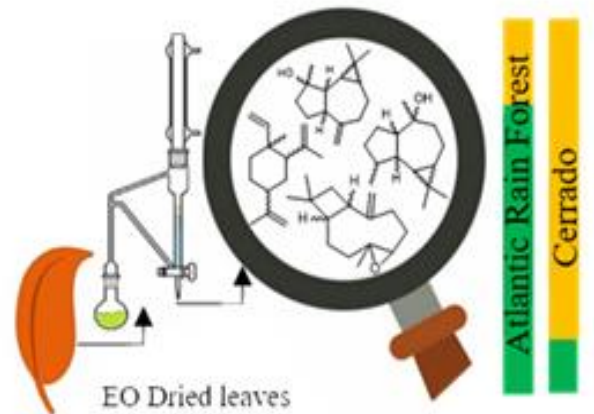

Oxygenated sesquiterpenes

Comparative study on volatile compounds of the in natura leaves (TD-CGMS) and dried leaf essential oil (GC-MS) from two Casearia sylvestris populations. 


\section{Introduction}

Casearia sylvestris Swartz (Salicaceae) is an important medicinal plant which is employed throughout Latin America (Xia et al., 2015). The essential oil (EO) from $C$. sylvestris leaves displays several biological and pharmacological activities, including antimicrobial, antileishmanial, antitumor, antiulcerogenic, and anti-inflammatory actions. Typically, the sesquiterpenes are the only compounds that are detected in this $\mathrm{EO}$, where $(E)$-caryophyllene, germacrene $\mathrm{D}, \alpha$-zingiberene, bicyclogermacrene, $\delta$ cadinene, and spathulenol predominate (Bou et al., 2013; Carvalho et al., 2018; Moreira et al., 2019; Spósito et al., 2019).

Artifacts generated during leaf drying and hydrodistillation may modify the leaf volatile chemical composition through chemical reactions, such as oxidation, rearrangement, ring-opening, and cyclization. Thus, leaves (in natura) and their respective EO have distinct volatile chemical profiles (Touaibia et al., 2019). Thermal desorption can be used to identify volatile components in plants without altering their original composition because this technique does not require leaf drying or hydrodistillation or the use of solvents (Arbulu et al., 2013).

The well-established application of $C$. sylvestris in Brazilian folk medicine and the pharmacological actions of its EO highlight that it can potentially be employed as the basis of medicines (Xia et al., 2015). However, the use of EOs as pharmaceutical raw material demands chemical standardization because genetic, environmental, and processing factors and storage may affect the EO chemical composition (Gobbo-Neto and Lopes, 2007; Kiazolu et al., 2016). Therefore, this study evaluates how drying and hydrodistillation (processing factors), as well as the geographical origin (environmental factor), impact the C. sylvestris var. sylvestris leaf volatile chemical composition by comparing the chemical composition of the volatile fraction of in natura leaves and dried leaf EO obtained from two $C$. sylvestris var. sylvestris populations collected from different Brazilian biomes (Atlantic Forest and Cerrado).

\section{Experimental}

\subsection{Plant material}

Casearia sylvestris Swartz var. sylvestris leaves were collected from 10 specimens of each of the two populations, designated $\mathrm{CB}$ and $\mathrm{SA}$, in December 2016. The CB population: Carlos Botelho State Park, São Miguel Arcanjo, São Paulo, Brazil (243'42"8 243'84"0 S, 4759'45"4-47059'80"5 W); Atlantic Rain Forest biome. The SA population: School of Agriculture, Botucatu (22 50'22"5-22 50'94"8 S, $48^{\circ} 25^{\prime} 50^{\prime \prime} 6-48^{\circ} 25^{\prime} 63^{\prime \prime} 7 \mathrm{~W}$ ); Cerrado biome. The specimens were identified by Dr. Luis V. S. Sacramento from the School of Pharmaceutical Sciences, Unesp, and the voucher specimens were deposited at the Herbarium "D. Bento Pickel" under the codes CB 51.816-51.826 and SA 301-310. This study was registered in the National System for the Management of Genetic Heritage and Associated Traditional Knowledge of Brazil (SisGen) under No. AEFB157.

\subsection{Essential oil extraction}

The leaves of each specimen were separately dried in an oven with air circulation at $40{ }^{\circ} \mathrm{C}$ for 3 days. The dried leaves $(30 \mathrm{~g})$ of each specimen were separately extracted by hydrodistillation in a clevenger-type apparatus for $4 \mathrm{~h}$ (Anvisa, 2010). The EO yield of the $\mathrm{CB}$ and $\mathrm{SA}$ populations was $1.3 \pm 0.2$ and $0.9 \pm 0.3 \%$ (v/w), respectively.

\subsection{Gas chromatography-mass spectrometry (GC- MS)}

Gas chromatography mass spectrometry analyses were performed on a Shimadzu QP2010 Plus (Shimadzu Corporation, Kyoto, Japan) system equipped with an AOC-20i autosampler and fitted with a Rtx-5MS capillary column (5\% diphenyl and 95\% polydimethylsiloxane, $30 \mathrm{~m} \times 0.25 \mathrm{~mm}, 0.25-\mu \mathrm{m}$ film thickness). Helium (99.9999\%) was used as the carrier gas $\left(1.0 \mathrm{~mL} \mathrm{~min}{ }^{-1}\right)$. The samples were prepared by mixing the EO obtained from the 10 specimens of a given population, $\mathrm{CB}$ or SA. Next, $1.0 \mu \mathrm{L}$ of the sample $\left(0.3 \mu \mathrm{L} \mathrm{mL} \mathrm{m}^{-1}\right.$, hexane) was injected and analyzed in the split mode (1:10). The injector and the ion source temperature were 240 and $280{ }^{\circ} \mathrm{C}$, respectively; the oven temperature was programmed to rise from 60 to $250{ }^{\circ} \mathrm{C}\left(3{ }^{\circ} \mathrm{C} \mathrm{min}{ }^{-1}, 80 \mathrm{~min}\right)$. The electron ionization mass spectra were obtained at 70 $\mathrm{eV}$ and recorded with a scan interval of $0.5 \mathrm{~s}$ for masses ranging from 40 to $600 \mathrm{Da}$. 


\subsection{Thermal desorption-gas chromatography- mass spectrometry (TD-GC-MS)}

The $C$. sylvestris leaves $\left(0.5 \mathrm{~mm}^{2}\right)$ were inserted into a glass tube $(0.63 \times 8.89 \mathrm{~cm}$, Supelco $)$ with glass wool around it. The volatile components were concentrated (5 min) on a Shimadzu TD-20 (Shimadzu Corporation, Kyoto, Japan) thermal desorption system fitted to a Shimadzu QP2010 Plus (Shimadzu Corporation, Kyoto, Japan) system by using the chromatographic conditions described above.

\subsection{Essential oil chemical identification}

The EO components were identified on the basis of the linear retention indices relative to a homologous series of $n$-alkanes $\left(\mathrm{C}_{8}-\mathrm{C}_{40}\right.$ Sigma-Aldrich) (Adams, 2007; Van Den Dool and Kratz, 1963) and the retention times of authentic $(E)$-caryophyllene, $\alpha$ humulene and caryophyllene oxide standards (Sigma-
Aldrich). The acquired spectra were computer-matched with reference spectra of the mass spectral libraries (NIST 08, WILEY 7 and FFNSC 1.2), and the fragmentation were compared to the fragmentation patterns (Kiazolu et al., 2016).

\section{Results and discussion}

Sesquiterpenes were the only compounds in the in natura leaf volatile fraction (Tab. 1, Figs. 1 and 2). These results agreed with the results of most studies on C. sylvestris EO. On the other hand (Sousa et al., 2007), monoterpenes and phenylpropanoids were identified as minor $C$. sylvestris EO components. According to literature data, sesquiterpene hydrocarbons predominate in C. sylvestris fresh leaf and dried leaf EO (Bou et al., 2013; Moreira et al., 2019; Spósito et al., 2019). However, the dried leaf EO of the populations CB and SA showed higher content of oxygenated sesquiterpenes.

Table 1. Volatile chemical composition of $C$. sylvestris var. sylvestris in natura leaves and dried leaf EO as determined by GC-MS analyses. The EO from the CB or SA population consisted of the EO that was extracted from10 specimens of each population.

\begin{tabular}{|c|c|c|c|c|}
\hline Components population & $\begin{array}{c}\text { CB in natura leaves } \\
(\%)\end{array}$ & $\begin{array}{c}\text { CB dried leaf EO } \\
(\%)\end{array}$ & $\begin{array}{c}\text { SA in natura leaves } \\
(\%)\end{array}$ & $\begin{array}{c}\text { SA dried leaf EO } \\
(\%)\end{array}$ \\
\hline$\alpha$-copaene & - & 0.2 & 0.7 & 0.6 \\
\hline$\delta$-elemene & 3.6 & - & 5.9 & 0.2 \\
\hline$\beta$-elemene & 1.6 & 12.2 & 2.8 & 1.7 \\
\hline$\beta$-boubornene & - & 0.2 & - & - \\
\hline$\gamma$-gurjunene & - & 0.9 & - & - \\
\hline (E)-caryophyllene ${ }^{1}$ & 32.5 & 0.9 & 1.9 & - \\
\hline$\beta$-copaene & 0.7 & - & - & - \\
\hline$\gamma$-elemene & 0.7 & - & - & - \\
\hline aromadendrene & 5.6 & 1.2 & 3.1 & 0.9 \\
\hline$\alpha$-humulene ${ }^{1}$ & 3.6 & 0.2 & - & 0.7 \\
\hline$\alpha$-gurjunene & 0.5 & - & - & - \\
\hline 9-epi-(E)-caryophyllene & - & 0.2 & - & 0.3 \\
\hline$\gamma$-muurolene & 0.5 & - & - & 0.5 \\
\hline$\alpha$-muurolene & - & 0.2 & - & 0.3 \\
\hline germacrene D & 7.0 & - & 5.5 & - \\
\hline$\beta$-selinene & - & 4.3 & 5.2 & 2.2 \\
\hline$\gamma$-patchoulene & - & 0.9 & - & - \\
\hline (Z)-calamenene & - & - & - & 4.6 \\
\hline bicyclogermacrene & 22.1 & - & 32.8 & - \\
\hline$\gamma$-cadinene & 0.4 & 0.6 & - & - \\
\hline$\delta$-cadinene & 0.8 & - & - & - \\
\hline germacrene B & - & 1.7 & - & - \\
\hline Sesquiterpene hydrocarbons & 79.0 & 23.7 & 57.9 & 12.0 \\
\hline silphyperfol-5-en-3-ol A & - & 2.3 & - & - \\
\hline globulol & - & - & - & 10.5 \\
\hline ledol & - & 0.9 & - & 2.7 \\
\hline palustrol & - & 1.9 & - & 1.4 \\
\hline
\end{tabular}


Original article

iq.unesp.br/ecletica

\begin{tabular}{|l|c|c|c|c|}
\hline spathulenol & 8.7 & 16.7 & 16.7 & 30.0 \\
\hline viridiflorol $^{\text {caryophyllene oxide }}{ }^{\mathrm{a}}$ & 1.5 & 3.1 & - & 3.3 \\
\hline humulene epoxide II & 1.7 & 21.6 & - & - \\
\hline bulnesol & - & 3.6 & - & 9.3 \\
\hline$\alpha$-muurolol & - & 4.4 & - & - \\
\hline cubenol & - & 0.5 & - & - \\
\hline$(Z)$-cadin-4-en-7-ol & - & 0.3 & - & 2.4 \\
\hline$(Z)$ - $\alpha$-santalol & - & 0.6 & - & - \\
\hline Oxygenated sesquiterpenes & - & 2.5 & $\mathbf{1 6 . 7}$ & \\
\hline Identified compounds & $\mathbf{1 0 . 4}$ & $\mathbf{5 8 . 4}$ & $\mathbf{6 1 . 3}$ \\
\hline
\end{tabular}

${ }^{\mathrm{a}}$ Compounds identified by comparison with the retention times of authentic standards.
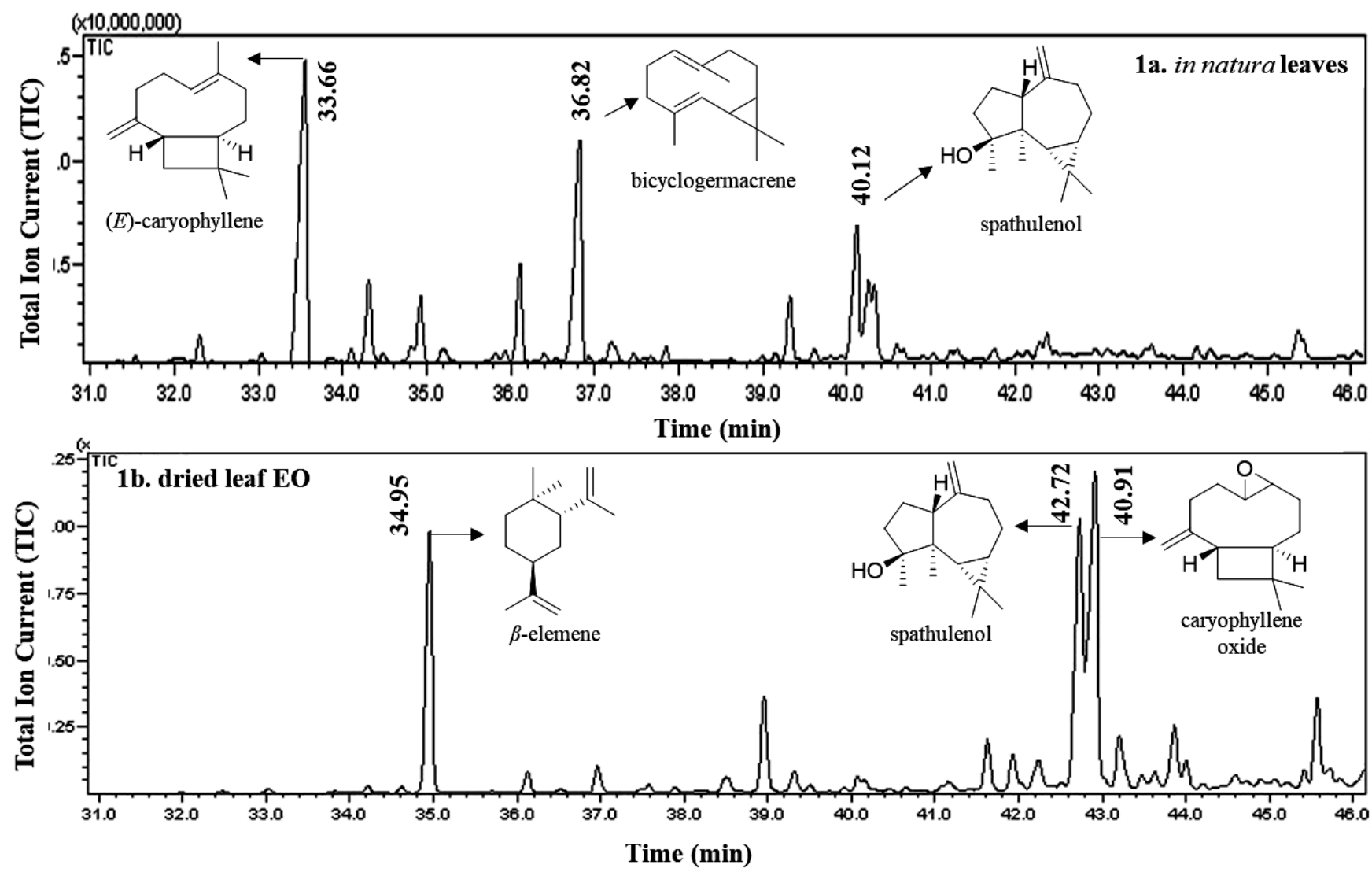

Figure 1. Essential oil expanded chromatograms (31-46 min) of $\mathrm{CB}$ population (each sample represents the EO mixture of the leaves of 10 specimens): volatile components in the in natura leaves (a) and dried leaf EO (b). Chromatographic conditions: capillary column Rtx5-MS (30 $\mathrm{m} \times 0.25 \mathrm{~mm}$ i.d., $0.25-\mu \mathrm{m}$ film thickness), 60 $310^{\circ} \mathrm{C}, 3{ }^{\circ} \mathrm{C} \mathrm{min}^{-1}$, for $80 \mathrm{~min}$; injector temperature $=250{ }^{\circ} \mathrm{C}$; split mode 1:10. 

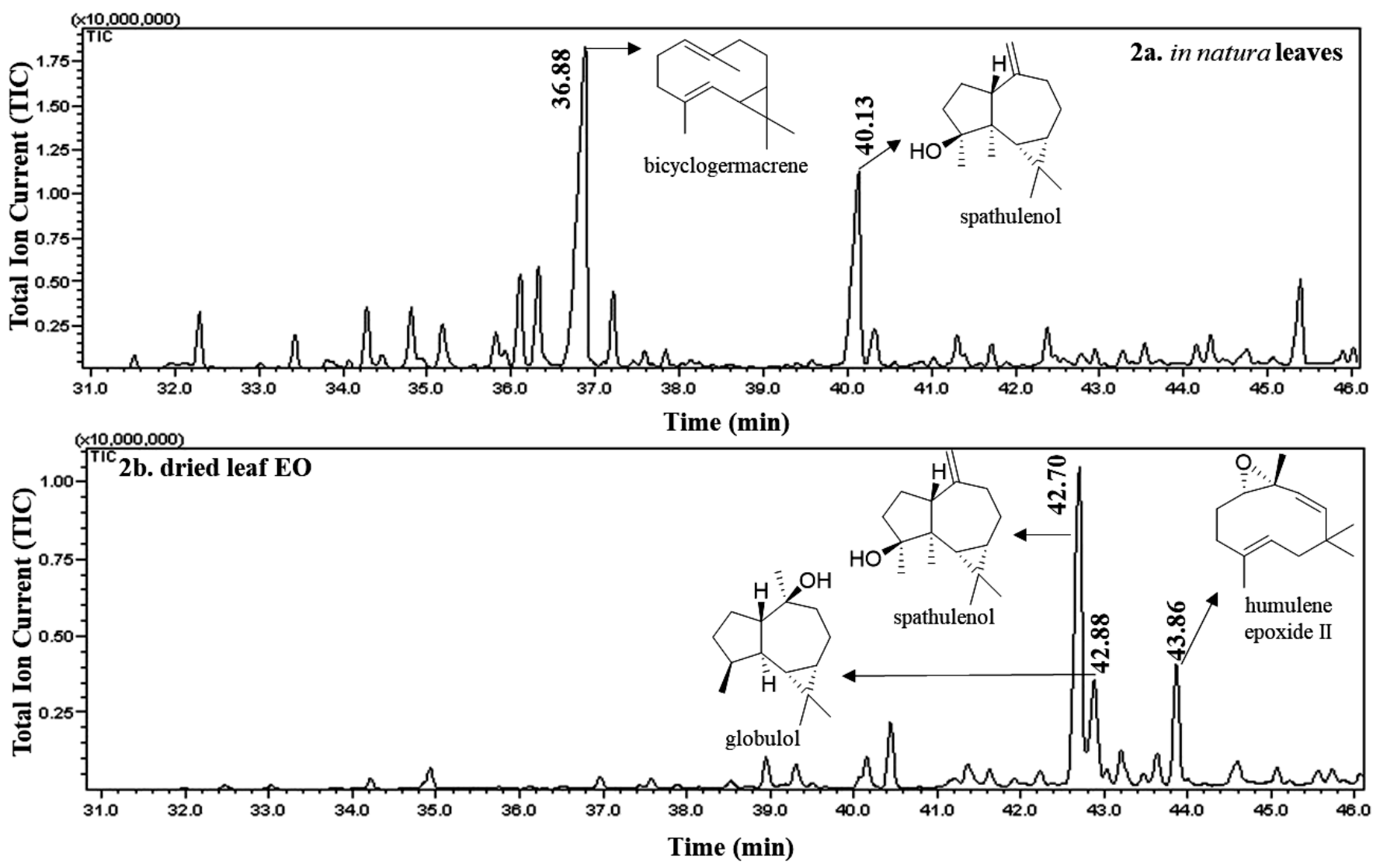

Figure 2. Essential oil expanded chromatograms (31-46 min) of SA population (each sample represents the EO mixture of the leaves of 10 specimens): volatile components in the in natura leaves (a) and dried leaf EO (b). Chromatographic conditions: capillary column Rtx5-MS $(30 \mathrm{~m} \times 0.25 \mathrm{~mm}$ i.d., $0.25-\mu \mathrm{m}$ film thickness), 60 $310^{\circ} \mathrm{C}, 3{ }^{\circ} \mathrm{C} \mathrm{min}^{-1}$, for $80 \mathrm{~min}$; injector temperature $=250{ }^{\circ} \mathrm{C}$; split mode $1: 10$.

The sesquiterpene hydrocarbon content in the $\mathrm{CB}$ population in natura leaves and dried leaf EO was 79.0 and $23.7 \%$, respectively, while the oxygenated sesquiterpene content in the $\mathrm{CB}$ population in natura leaves and dried leaf EO was 10.4 and $58.4 \%$, respectively. Data for the SA population revealed the same trend: the sesquiterpene hydrocarbon content in the in natura leaves and dried leaf EO was 57.9 and $16.7 \%$, respectively, whereas the oxygenated sesquiterpene content was 12.0 and $61.3 \%$, respectively (Tab. 1). The oxygenated sesquiterpene content increased after leaf drying and hydrodistillation, probably because oxidation reactions converted sesquiterpene hydrocarbons into oxygenated sesquiterpenes (Gopalakrishnan, 1994; Touaibia et al., 2019).

The major volatile constituents in the $\mathrm{CB}$ population (Fig. 3) in natura leaves were (E)caryophyllene $(32.5 \%)$ and bicyclogermacrene (22.1\%), whilst $\beta$-elemene (12.2\%), spathulenol
(16.7\%) and caryophyllene oxide $(21.6 \%)$ were the main components in the dried leaf EO. In the SA population, the main components (Fig. 3) in the in natura leaves were bicyclogermacrene $(32.8 \%)$ and spathulenol (16.7\%), whereas spathulenol $(30.0 \%)$ was predominant in the dried leaf EO. According to the literature, the main $C$. sylvestris leaf EO components are $(E)$-caryophyllene, $\alpha$-zingiberene, germacrene $\mathrm{D}$, bicyclogermacrene, $\delta$-cadinene, and spathulenol (Bou et al., 2013; Carvalho et al., 2018; Moreira et al., 2019; Spósito et al., 2019), which partially match the major compounds that were identified in the $\mathrm{CB}$ and SA populations.

Here, the sesquiterpenes 9-epi-(E)-caryophyllene, silphyperfol-5-en-3-ol A, (Z)-cadin-4-en-7-ol, and (Z)$\alpha$-santalol have been identified in the $C$. sylvestris leaves for the first time (Tab. 1); silphyperfol-5-en-3-ol $\mathrm{A}$ and (Z)- $\alpha$-santalol were detected in the CB population only. 


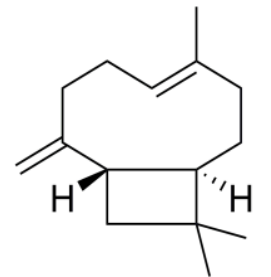

(E)-caryophyllene<smiles>CC1=CC2C(CCC=C(C)C2(C)C)CCC1</smiles>

bicyclogermacrene<smiles>C=C(C)[C@@H]1CCC(C)(C)[C@H](C(=C)C)C1</smiles>

$\beta$-elemene<smiles>C=C1CCC2[C@H](C1(C)C)[C@@]1(C)CC[C@]2(C)C1(C)C</smiles>

spathulenol

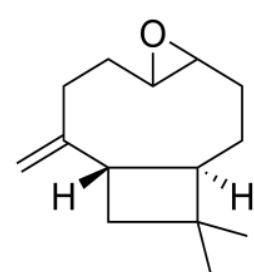

(E)-caryophyllene

Figure 3. Chemical structures of the major components in $C$. sylvestris leaf volatiles.

In the $\mathrm{CB}$ population, the $(E)$-caryophyllene content decreased from $32.5 \%$ in the in natura leaves to $0.9 \%$ in the dried leaf EO, while the caryophyllene oxide content increased from 1.7 to $21.6 \%$. According to data literature (Sköld et al., 2006), during (E)-caryophyllene (standard) exposure to air, this compound underwent total degradation, to generate caryophyllene oxide through hydroperoxide reactions. However, the conversion into caryophyllene oxide was about $40 \%$, which led to the conclusion that drying and hydrodistillation may produce chemical oxidation reactions that convert (E)-caryophyllene into caryophyllene oxide.

The bicyclogermacrene content in the CB population decreased from $22.1 \%$ in the in natura leaves to not detected in the dried leaf EO, while the spathulenol and viridiflorol contents increased from 8.7 and $1.5 \%$ in the in natura leaves to 16.7 and $3.1 \%$ in the dried leaf EO, respectively. In the SA population, the bicyclogermacrene content decreased from $32.8 \%$ in the in natura leaves to not detected in the dried leaf EO, whilst the spathulenol, viridiflorol, and globulol contents increased from $16.7 \%$, not detected, and not detected in the in natura leaves to $30.0,3.3$, and $10.5 \%$ in the dried leaf EO, respectively. These results indicated that bicyclogermacrene may have been oxidized and converted into spathulenol, viridiflorol, and globulol during drying and hydrodistillation (Nascimento et al., 2018; Njoroge et al., 1996; 2003; Telascrea et al., 2008; Toyota et al., 1996).

\section{Conclusion}

In summary, these results demonstrated qualitative and quantitative chemical variability between the $C$. sylvestris var. sylvestris populations from Cerrado and Atlantic Forest and generation of oxygenated degradation products from sesquiterpene hydrocarbons during drying and/or hydrodistillation. This study also reinforced the potential of thermal desorption to determine the chemical composition of volatile compounds in natura.

\section{Authors' contribution}

Conceptualization: Carvalho, F. A.; Crotti, A. E. M.; Santos, A. G.

Data curation: Carvalho, F. A.; Oda, F. B.; Crevelin, E. J.

Formal Analysis: Carvalho, F. A.; Oda, F. B.; Crevelin, E. J.; Crotti, A. E. M.; Santos, A. G.

Funding acquisition: Santos, A. G.

Investigation: Carvalho, F. A.; Oda, F. B.; Crevelin, E. J.

Methodology: Carvalho, F. A.; Santos, A. G.

Project administration: Santos, A. G.

Resources: Not applicable.

Software: Not applicable.

Supervision: Crotti, A. E. M.; Santos, A. G.

Validation: Not applicable.

Visualization: Santos, A. G.

Writing - original draft: Carvalho, F. A.; Oda, F. B.

Writing - review \& editing: Crevelin, E. J.; Crotti, A. E. M.; Santos, A. G.

\section{Data availability statement}

The data will be available upon request.

\section{Funding}

This study was partially funded by Coordination for the Improvement of Higher Education Personnel (CAPES), Finance Code 001.

\section{Acknowledgments}

We thank Dr. Luiz Alberto Beraldo de Moraes for his collaboration with TD and GC-MS equipment analysis.

\section{References}

Adams, R. P. Identification of Essential Oil Components by Gas Chromatography/Mass Spectrometry, Allured Publishing Corporation, 2007. 
Agência Nacional de Vigilância Sanitária (Anvisa). Farmacopeia Brasileira; Anvisa, 2010.

Arbulu, M.; Sampedro, M. C.; Sanchez-Ortega, A.; GómezCaballero, A.; Unceta, N.; Goicolea, M. A.; Barrio, R. J. Characterisation of the flavour profile from Graciano Vitis vinifera wine variety by a novel dual stir bar sorptive extraction methodology coupled to thermal desorption and gas chromatography-mass spectrometry. Anal. Chim. Acta 2013, 777, 41-48. https://doi.org/10.1016/j.aca.2013.03.024.

Bou, D. D.; Lago, J. H. G.; Figueiredo, C. R.; Matsuo, A. L.; Guadagnin, R. C.; Soares, M. G.; Sartorelli, P. Chemical composition and cytotoxicity evaluation of essential oil from leaves of Casearia sylvestris, its main compound $\alpha$ zingiberene and derivatives. Molecules 2013, 18 (8), 94779487. https://doi.org/10.3390/molecules18089477.

Carvalho, F. A.; Aguilar, P. P.; Oda, F. B.; Uchina, H. S.; Tininis, A. G.; Crevelin, E. J.; Crotti, A. E. M.; Santos, A. G. Chemical variability between different organs of the medicinal plant Casearia sylvestris. Rev. Ciênc. Farm. Básica Apl. 2018, 39, e639.

Gobbo-Neto, L.; Lopes, N. P. Plantas medicinais: Fatores de influência no conteúdo de metabólitos secundários. Quím. Nova 2007, 30 (2), 374-381. https://doi.org/10.1590/S010040422007000200026 .

Gopalakrishnan, N. Studies on the storage quality of carbon dioxide-extracted cardamom and clove bud oils. J. Agric. Food Chem. 1994, 42 (3), 796-798. https://doi.org/10.1021/jf00039a039.

Kiazolu, J. B.; Intisar, A.; Zhang, L.; Wang, Y.; Zhang, R.; Wu, Z.; Zhang, W. Phytochemical screening and chemical variability in volatile oils of aerial parts of Morinda morindoides. Nat. Prod. Res. 2016, 30 (19), 2249-2252. https://doi.org/10.1080/14786419.2016.1154058.

Moreira, R. R. D., Santos, A. G., Carvalho, F. A., Perego, C. H., Crevelin, E. J., Crotti, A. E. M., Cogo, J., Cardoso, M. L. C., Nakamura, C.V. Antileishmanial activity of Melampodium divaricatum and Casearia sylvestris essential oils on Leishmania amazonensis. Ver. Inst. Med. Trop. S. Paulo 2019, 61, e33. https://doi.org/10.1590/s16789946201961033.

Nascimento, K. F. do; Moreira, F. M. F.; Santos, J. A.; Kassuya, C. A. L.; Croda, J. H. R.; Cardoso, C. A. L.; Vieira, M. C.; Ruiz, A. L. T. G.; Foglio, M. A.; Carvalho, J. E.; Formagio, A. S. N. Antioxidant, anti-inflammatory, antiproliferative and antimycobacterial activities of the essential oil of Psidium guineense Sw. and spathulenol. J. Ethnopharmacol. 2018, 210, 351-358. https://doi.org/10.1016/j.jep.2017.08.030.

Njoroge, S. M.; Ukeda, H.; Sawamura, M. Changes in the volatile composition of yuzu (Citrus junos Tanaka) cold- pressed oil during storage. J. Agric. Food Chem. 1996, 44 (2), 550-556. https://doi.org/10.1021/jf950284k.

Njoroge, S. M.; Ukeda, H.; Sawamura, M. Changes of the volatile profile and artifact formation in Daidai (Citrus aurantium) cold-pressed peel oil on storage. J. Agric. Food Chem. 2003, 51 (14), 4029-4035. https://doi.org/10.1021/jf021215q.

Sköld, M.; Karlberg, A.-T.; Matura, M.; Börje, A. The fragrance chemical $\beta$-caryophyllene-air oxidation and skin sensitization. Food Chem. Toxicol. 2006, 44 (4), 538-545. https://doi.org/10.1016/j.fct.2005.08.028.

Sousa, F. G.; Schneider, N. F. Z.; Mendes, C. E.; de Moura, N. F.; Denardin, R. B. N.; Matuo, R.; Mantovani, M. S. Clastogenic and Anticlastogenic Effect of the Essential Oil from Casearia sylvestris Swart. J. Essent. Oil Res. 2007, 19 (4), $376-378$ https://doi.org/10.1080/10412905.2007.9699309.

Spósito, L.; Oda, F. B.; Vieira, J. H.; Carvalho, F. A.; Ramos, M. A. S.; Castro, R. C.; Crevelin, E. J.; Crotti, A. E. M.; Santos, A. G.; da Silva, P. B.; Chorilli, M.; Bauab, T. M. In vitro and in vivo anti-Helicobacter pylori activity of Casearia sylvestris leaf derivatives. J. Ethnopharmacol. 2019, 233, 1-12. https://doi.org/10.1016/j.jep.2018.12.032.

Telascrea, M.; de Araújo, C. C.; Cavalheiro, A. J.; Marques, M. O. M.; Facanali, R.; de Moraes, P. L. R. Essential oils from leaves of Cryptocarya spp from the atlantic rain forest. Quím. Nova 2008, $31 \quad$ (3), 503-507. https://doi.org/10.1590/S0100-40422008000300007.

Touaibia, T.; Boutekedjiret, T. C.; Perino, S.; Chemat, F. Natural Terpenes as Building Blocks for Green Chemistry. In Plant Based "Green Chemistry 2.0"; Li, Y.; Chemat, F., Eds.; $\quad$ Springer, 2019; pp 171-195. https://doi.org/10.1007/978-981-13-3810-6_7.

Toyota, M.; Koyama, H.; Mizutani, M.; Asakawa, Y. (-)ent-spathulenol isolated from liverworts is an artefact. Phytochemistry 1996, $41 \quad$ (5), 1347-1350. https://doi.org/10.1016/0031-9422(95)00798-9.

Van Den Dool, H., Kratz, P. D. A Generalization of the Retention Index System Including Linear Temperature Programmed Gas-Liquid Partition Chromatography. J. Chromatogr. A 1963, 11, 463-471. https://doi.org/10.1016/S0021-9673(01)80947-X.

Xia, L.; Guo, Q.; Tu, P.; Chai, X. The genus Casearia: a phytochemical and pharmacological overview. Phytochem. Rev. 2015, 14, 99-135. https://doi.org/10.1007/s11101-0149336-6. 